\title{
NEW MOUTH CANCER CENTRE FOR LONDON
}

A new cancer centre is being set up to improve survival rates and quality of life for thousands of people affected by squamous cancer - a specific type of cancer which affects the mouth, skin, lungs and cervix.

The centre, which will be based at Queen Mary University of London's Blizard Institute in Whitechapel, will bring together clinical and research experts to explore who is at risk of developing squamous cancer and why.

More than 70,000 people are diagnosed with squamous cancer every year in the UK. It is the most common cause of solid tumours and results in many deaths.

The Barts Centre for Squamous Cancer is being set up with a $£ 2.6$ million grant from Barts Charity, and will focus on mouth cancer as this is a particularly common problem among the local East London population.

Mouth cancer has increased by $58 \%$ over the past decade, yet despite more than 8,700 people being diagnosed every year across the UK, only one in five people know the main signs and symptoms.

Many patients will not survive for five years after being diagnosed, and for those who do, treatment can be harsh and disfiguring, often leaving a devastating impact on a person's appearance and ability to eat, drink and speak.

Smoking, alcohol, diet, and various viruses all increase an individual's risk of developing oral cancer, and it is a particular problem in areas of high social deprivation, and among certain groups, such as South Asian communities.

In the London Borough of Tower Hamlets, the rate has risen by a third over the past decade to 21.5 people per 100,000 , and it continues to increase among younger adults due to tobacco use.

Paul Coulthard, Professor of Oral \& Maxillofacial Surgery at Barts and The London School of Medicine and Dentistry at Queen Mary University of London, said: 'Oral cancer has been underfunded for many years, and we hope that by bringing our expertise together in this new centre we will be able to develop a better understanding of mouth cancer. Awareness of risk factors and symptoms is still very low, and we hope our work will improve detection, diagnosis, and access to treatment.

'We know that the risk of being diagnosed with oral cancer is strongly associated with social deprivation, and this is a particular health challenge in London. This centre will enable us to develop a much better understanding of who is at risk and why, so that we can improve treatment and the quality of life for all those affected, both in the UK and wider afield.'

The Barts Centre for Squamous Cancer will bring together clinical and research experts who will work with patient groups, run clinical trials, and build a human tissue bank to improve knowledge and understanding of squamous cancer.

\section{HISTORIC DAY FOR NEW COLLEGE OF GENERAL DENTISTRY}

1 July marked a momentous day in the history of dentistry in the UK as the College of General Dentistry officially opened in a ceremony at the Barber Surgeons Hall. Dentistry now has its own, independent College.

The new College of General Dentistry (CGDent) embraces the whole dental team, recognising the invaluable contribution made by every member of the dental profession in delivering high quality oral health care for patients and the wider community.

As Dr Abhi Pal takes office as the first elected President of the College, he said of the historic day: 'The College of General Dentistry looks forward to providing new leadership, much-needed career pathways, fit-for-purpose standards and cutting edge, evidence-based guidelines with much more besides. Going forward we intend to build on the fabulous legacy provided by the FGDP and to further raise the standing and status of dentistry as an important, integral, never-to-be-forgotten element of health and social care. The College considers oral health to be fundamental to general health and wellbeing at all ages'.
The College is ready to welcome all oral healthcare professionals into its membership.

The move to an independent college for dentistry will finally realise the long-held ambition of those who founded the Faculty of General Dental Practitioners (UK) in 1992. It was their foresight, hard work and commitment to general dental practice which allowed them to establish FGDP(UK) driven by the vision that one day dentistry would have a Royal College. The new independent College is not quite at the stage of applying for a Royal Charter, but the move to an independent College of General Dentistry is a giant step closer to that ambition.

The College will set standards and provide guidance, encouraging and recognising continuing professional development. And importantly, it will provide a unified collegiate voice for all oral healthcare professionals.

Engagement in the College, both individually and collectively, has the potential to positively transform the standing and status of every member of the team, both in general healthcare and in the eyes of the public.

The College, with a membership open to all General Dental Council (GDC) registrants (past and present), together with suitably qualified colleagues from across the rest of the world, is for all members of the dental team to benefit and contribute to a new, rewarding future for dentistry. Members will be able to access a rich library of online CPD, courtesy of partners ProDental. They will also be able to access a programme of webinars through the year tailored for the College's membership.

https://cgdent.uk/ 